\section{COVID-19 associated hyperthyroidism due to destructive thyrotoxicosis in a young female patient}

\author{
Zeilberger MS ${ }^{1 * \#}$, Hasmann $\mathrm{SE}^{2 * \#}$, Auer $\mathrm{MK}^{1}$ and Schmidmaier $\mathbf{R}^{1}$ \\ ${ }^{1}$ Medical Department IV, Endocrinology, Diabetology, University Hospital of Munich, Ziemsenstr 1 \\ 80336 München, Germany \\ ${ }^{2}$ Medical Department IV, Nephrology, University Hospital of Munich, Ziemsenstr. 1, 80336 \\ München, Germany \\ \#Contributed equally
}

\section{Abstract}

SARS-CoV2 can induce multiple immunological and endocrinological changes. We report the case of a COVID-19 associated hyperthyroidism in a young female.

Per definition the patient - because of having given birth six weeks previously - had a postpartum thyroiditis. However thus no antibodies were detected, the thyroiditis ceased without medication after the dissolving of the virus disease and the fT3/fT3-ratio proved a destructive thyreopathy as well as there was a close time link onset of the symptoms with the novel corona virus infection we argue it to be a COVID-19 induced thyrotoxicosis.

This proves the ability of SARS-CoV-2 to alter thyroid function, therefore all COVID-19 patients should be monitored regarding endocrinological changes and TSH, fT3, fT4 should be assessed.

\section{Introduction}

COVID-19 is known by now to have the ability to induce various endocrinological changes in its hosts. Until now only a few affections regarding the thyroid have been described.

We report a case of a COVID-19 induced destructive thyrotoxicosis.

\section{Case presentation}

In March 2020, a 35 years old female patient presented to the emergency room (ER) because of holocephalic headache and tachycardia. Symptoms had developed 5 days before the patient's presentation to our ER. She did not suffer from coughing, dyspnoea or other respiratory tract symptoms. The patient was originally from Nigeria and had been living in Germany for four years. She had no medical history apart from having delivered a child six weeks ago. She had not been travelling to any- back then- stated COVID-19 risk areas and had no known contact to anyone being tested positive for SARS-CoV-2 but was living in a refugee shelter in Munich.

Upon arrival in the ER, an elevated temperature of $38.2^{\circ} \mathrm{C}$ 4.20]).

\section{More Information}

\begin{abstract}
*Address for Correspondence: Mira Stephanie Zeilberger, MD, Medical Department IV, Endocrinology, Diabetology, University Hospital of Munich, Ziemsenstr 1, 80336, München, Germany,

Email: mira.zeilberger@med.uni-muenchen.de

Hasmann Sandra Elisabeth, MD, PhD, M.Sc.,

Medical Department IV, Nephrology, University Hospital of Munich, Ziemsenstr 1, 80336,

München, Germany,

Email: Sandra.hasmann@med.uni-muenchen.de

Submitted: 03 July 2020

Approved: 25 July 2020

Published: 27 July 2020

How to cite this article: Zeilberger MS, Hasmann SE, Auer MK, Schmidmaier R. COVID-19 associated hyperthyroidism due to destructive thyrotoxicosis in a young female patient. Ann Clin Endocrinol Metabol. 2020; 4: 023-025.
\end{abstract}

DOI: 10.29328/journal.acem.1001016

Copyright: @ 2020 Zeilberger MS, et al. This is an open access article distributed under the Creative Commons Attribution License, which permits unrestricted use, distribution, and reproduction in any medium, provided the original work is properly cited.

\section{(W) Check for updates}

(8) OPEN ACCESS

was measured. The patient herself stated that she felt like having fever the day before going to the ER, but temperature hadn't been measured. The initial ECG showed a sinus tachycardia with a frequency of up to 120 beats per minute. Laboratory results revealed elevated thyroid hormone levels (fT3 $5.8 \mathrm{pg} / \mathrm{ml}$; [2.0-4.4]; fT4 $21 \mathrm{pg} / \mathrm{ml}$; [9-17]; ^ fT3/fT4ratio: 0.276$)$ as well as a supressed TSH $(0.02 \mu \mathrm{U} / \mathrm{ml}$; [0.27-

C reactive protein, interleukin-6, procalcitonin and erythrocyte sedimentation rate were normal on admission. Upon day 3 the $C$ reactive protein rose to a level of $2,2 \mathrm{mg} /$ dl. Full blood count was normal but differential revealed lymphopenia (1.18 G/l; [1.22-3.56]) and eosinopenia $(<0.01$ G/l; [0.03-0.44]). The thyroid ultrasound showed a normal size with slightly hypoechogenic, homogenous texture with hypoperfusion and without any thyroid nodules. The patient presented no signs for endocrine orbitopathy. The thyroid was not painful or tender. There was no family history for endocrinological diseases nor antibodies. Pregnancy was ruled out by serum human chorionic gonadotropin. Blood was taken to determine thyroid autoantibodies. Due to the 
initially unclear ethology of hyperthyroidism, she received 20 mg carbimazole once, nonsteroidal antiphlogistic drugs and propranolol and was scheduled for admission to the hospital ward.

According to the local ER algorithm during SARS-CoV-2 pandemic a throat swab for SARS-CoV-2-PCR and a computed tomography of the chest were performed because of fever and eosinopenia. CT scan revealed a few areas with patchy confluent opacifications in the upper right lobe and SARSCoV-2-PCR was positive. Therefore, the patient was admitted to the COVID-19 isolation unit.

In summary, hyperthyroidism due to painless thyroiditis and COVID-19 were diagnosed.

The course of COVID-19 remained mild with sore throat and headaches as the only symptoms. Lactate dehydrogenase increased to a maximum of $881 \mathrm{U} / \mathrm{l}[<250]$ on day 6 after admission, ferritin to a maximum of $758 \mathrm{ng} / \mathrm{ml}$ [15-150] on day 6 and $C$ reactive protein to a maximum of $3.3 \mathrm{mg} / \mathrm{dl}$ [ $\leq$ $0.5]$ on day 5 . She was discharged into home quarantine from hospital on day 10 .

As thyroid autoantibodies (antithyroid peroxidase (TPO) antibody, anti-thyroglobulin (Tg) antibody and thyroidstimulating hormone receptor (TSHR) antibody) were negative and thyroid ultrasound was not suggestive for Graves' disease or autonomy, carbimazole was not continued. Thyroid hormones started already dropping during the hospital stay without further medication. There was no indication for invasive diagnostics like thyroid biopsy/fine needle aspiration or thyroid scintigraphy. Four weeks later the patient presented for re-evaluation in our endocrinological outpatient clinic. Without taking any specific medication, thyroid hormones (fT3, fT4, TSH) had normalized. Also, COVID-19 inflammation markers had completely recovered. Thyroid antibodies continued to be negative and the ultrasound was still nonsuggestive for a thyroid disease.

\section{Discussion}

We report a case of thyrotoxicosis most likely induced by the novel coronavirus SARS-CoV-2. From our point of view the patient had a painless destructive thyreopathy with release of preformed thyroid hormones from the colloid space that resolved completely after a few weeks. Considering the long half-life of thyroid hormones, we assume that thyroid destruction was strong and brief. The course of thyroid dysfunction was closely related to the course of Corona virus disease. Brancatella and collegues already reported a similar case of a patient who was suffering from COVID-19 and developed hyperthyroidism. Like in our patient, thyroid antibodies were negative and thyroid function resolved completely within a short period of time without taking any thyreostatic medication [1].
Per definition the patient had a postpartum thyroiditis (PPT) if defined as the occurrence of de novo transient thyroid dysfunction in the first year after delivery in a previously euthyroid woman. However, PPT is thought to be a variant of chronic autoimmune thyroiditis (Hashimoto's thyroiditis) with rebound of thyroid antibodies after the immunosuppressive state of pregnancy [2]. TPO-Ab is positive in the majority of patients and $\mathrm{Tg}-\mathrm{Ab}$ may also be positive. In a prospective study 391 women were closely monitored for one year [3] after delivery. $24 \%$ of the 152 anti-TPO positive women developed hyperthyroidism during the first year postpartum, but zero percent of the 239 anti-TPO negative women developed any thyroid dysfunction! Although we can't completely rule out PPT, especially antibody-negative postpartum thyroiditis [2], due to the close time link onset of the symptoms with the virus infection as well as the fast dissolving of COVID-19 and the thyroiditis we would argue against this possibility. Moreover the FT3/FT4 ratio also points out a destruction induced thyrotoxicosis [4], even though as stated before, PPT can't be ruled out completely.

Viral diseases can cause a thyroiditis [5,6]. So far they have been reported for e.g. influenza [7-9], H1N1 [9], cytomegalovirus [10]. Especially for H1N1 even thyrotoxic storms have been reported [11]. Regarding H1N1 an overreaction of the systemic inflammation was proposed.

The thyroid injury is suspected to be the result of cytolytic $\mathrm{T}$-cell activation due to viral antigen presentation [6].

SARS-CoV2 has shown to have the ability to induce ARDS [12], myocarditis [13] and renal failure. These effects have been linked to induction of pro-inflammatory cell death due to an overreaction of the immune system [14], effects which can be linked to cytotoxic effects on the thyroid.

Additionally, SARS-CoV-2 binds via the envelope spike glycoprotein during cell entry to the angiotensin converting enzyme 2, which is expressed on the mostly affected organs by COVID-19 (lung, heart) as well as on endocrine tissue like the adrenal gland, hypophysis, pancreas [15] and the thyroid [16]. In autopsies from SARS-CoV no virus particles have been found in the thyroid gland unlike to the adrenal glands, pituitary and pancreas [17]. The described induction of hyperthyroidism could suggest the ability of SARS-CoV-2 to invade the thyroid. Whether this destruction was induced by cytopathic effects probably linked to local replication of SARS-CoV-2 or if they were the result of the systemic immune response remains uncertain and should be further evaluated. Particularly histopathological findings and understanding immune evasion strategies of SARS-CoV-2 will foster further knowledge regarding this question.

\section{Lessons learned}

We assume SARS-CoV-2 infection can induce a destruction of thyroid issue. All patients with COVID-19 should be 
monitored regarding endocrinological changes, especially diabetes, but also TSH, fT3, fT4 should be assessed. Hyperthyroidism may mimic clinical features of COVID-19 like fever, tachycardia, and diarrhoea. Thyroid dysfunction may be due to coincident primary thyroid disease, but also viral affection of the thyroid should be taken into account. For scientific reasons biopsy with SARS-CoV-2-PCR and immunohistology would be desirable in unclear cases.

Furthermore, treatment of thyroid disorders has become more challenging during the COVID-19 pandemic due to local lockdowns in certain areas and restricted access to hospitals and outpatient clinics. In particular patients with uncontrolled thyrotoxicosis are believed to be at a higher risk of severe complications if suffering from COVID-19 [18]. Therefore, it is important to monitor and follow-up patients with thyroid disorders, especially thyrotoxicosis and hyperthyroidism, closely [19]. Novel assessment and treatment concepts, such as telemedicine consultations [20], should be considered.

\section{Data availability}

All data are available via the cited sources.

\section{Funding statement}

The case report was performed as part of the employment of the authors at the University hospital of Munich, Endocrinology Department.

\section{References}

1. Brancatella A, Ricci D, Viola N, Sgro D, Santini $F$, et al. Subacute Thyroiditis After Sars-COV-2 Infection. J Clin Endocrinol Metab. 2020 105: 65-77.

PubMed: https://pubmed.ncbi.nlm.nih.gov/32436948/

2. Nguyen CT, Mestman JH. Postpartum Thyroiditis. Clini Obstet Gynecol. 2019; 62: 359-364.

PubMed: https://pubmed.ncbi.nlm.nih.gov/30844908/

3. Lazarus JH, Hall R, Parkes AB, Richard CJ, McCulloch B, et al. The Clinical Spectrum of Postpartum Thyroid Disease. QJM. 1996; 89: 429-435.

PubMed: https://www.ncbi.nlm.nih.gov/pubmed/8758046

4. Izumi Y, Hidaka Y, Tada H, Takano T, Kashiwai T, et al. Simple and Practical Parameters for Differentiation between Destruction-Induced Thyrotoxicosis and Graves' Thyrotoxicosis. Clini Endocrinol. 2020; 57: 51-58.

PubMed: https://pubmed.ncbi.nlm.nih.gov/12100069/

5. Marrif H. Thyroiditis, Secondary to Viral Infection. Front Endocrinol.2010; 10. PubMed: https://www.ncbi.nlm.nih.gov/pmc/articles/PMC3355905/

6. Desailloud R, Hober D. Viruses and Thyroiditis: An Update. Virol J. 2009.

7. Cunha BA, Berbari N. Subacute Thyroiditis (de Quervain's) Due to Influenza A: Presenting as Fever of Unknown Origin (FUO). Heart and
Lung. 2013; 42: 77-78.

PubMed: https://pubmed.ncbi.nlm.nih.gov/22819125/

8. Altay FA, Güz G, Altay M. Subacute Thyroiditis Following Seasonal Influenza Vaccination. Hum Vaccin Immunother. 2016; 12: 1033-1034. PubMed: https://www.ncbi.nlm.nih.gov/pmc/articles/PMC4962945/

9. Michas G, Alevetsovitis G, Andrikou I, Tsimiklis S, Vryonis E. De Quervain Thyroiditis in the Course of H1N1 Influenza Infection. Hippokratia. 2014; 18: 86-87.

PubMed: https://pubmed.ncbi.nlm.nih.gov/25125962/

10. Al Almundher A, Al Yaarubi S, Al Futaisi A. An Infant with Cytomegalovirus-Induced Subacute Thyroiditis. J Pediatr Endocrinol Metab. 2008; 21: 191-193.

PubMed: https://pubmed.ncbi.nlm.nih.gov/18422033/

11. Baharoon SA. H1N1 Infection-Induced Thyroid Storm. Ann Thorac Med. 2010; 5: 110-112.

PubMed: https://www.ncbi.nlm.nih.gov/pmc/articles/PMC2883193/

12. Li X, Ma X. Acute Respiratory Failure in COVID-19: Is It 'Typical' ARDS? Crit Care. 2020; 24: 198

PubMed: https://pubmed.ncbi.nlm.nih.gov/32375845/

13. Irabien-Ortiz Á, Carreras-Mora J, Sionis A, Pàmies J, Montiel J, et al Fulminant Myocarditis Due to COVID-19. Rev Esp Cardiol (Engl Ed). 2020; 73: 503-504.

PubMed: https://www.ncbi.nlm.nih.gov/pmc/articles/PMC7158782/

14. Felsenstein S, Herbert JA, McNamara PS, Hedrich CM. COVID-19: Immunology and Treatment Options. Clini Immunol. 2020; 215: 108448.

PubMed: https://pubmed.ncbi.nIm.nih.gov/32353634/

15. Zou X, Chen K, Zou J, Han P, Hao J, et al. Single-Cell RNA-Seq Data Analysis on the Receptor ACE2 Expression Reveals the Potential Risk of Different Human Organs Vulnerable to 2019-NCoV Infection. Front Med. 2020; 14: 185-192.

PubMed: https://pubmed.ncbi.nlm.nih.gov/32170560/

16. Meng-Yuan L, Li L, Zhang Y, Xiao-Sheng W. Expression of the SARSCoV-2 Cell Receptor Gene ACE2 in a Wide Variety of Human Tissues." Infectious Diseases of Poverty. 2020; 9: 45.

PubMed:: https://pubmed.ncbi.nlm.nih.gov/32345362/

17. Ding $Y$, He L, Zhang Q, Huang Z, Che $X$, et al. Organ Distribution of Severe Acute Respiratory Syndrome (SARS) Associated Coronavirus (SARS-CoV) in SARS Patients: Implications for Pathogenesis Virus Transmission Pathways. J Pathol. 2004; 203: 622-630.

PubMed: https://pubmed.ncbi.nlm.nih.gov/15141376/

18. Boelaert K, WE Visser, Taylor PN, Moran C, Léger J, et al. ENDOCRINOLOGY in the TIME of COVID-19: Management of Hyperthyroidism and Hypothyroidism. Eur J Endocrinol. 2020.

19. Bartalena L, Chiovato L, Marcocci C, Vitti P, Piantanida E, et al Management of Graves' Hyperthyroidism and Orbitopathy in Time of COVID-19 Pandemic. J Endocrinol Invest. 2020; 43: 1149-1151. PubMed: https://pubmed.ncbi.nlm.nih.gov/32441005

20. Griffith ML, Bischoff LA, Baum HBA. Approach to the Patient With Thyrotoxicosis Using Telemedicine. J Clin Endocrinol Metab. 2020; 105 dgaa373.

PubMed: https://pubmed.ncbi.nIm.nih.gov/32525973/

21. Doyen D, Moceri P, Ducreux D, Dellamonica J. Myocarditis in a Patient with COVID-19: A Cause of Raised Troponin and ECG Changes. Lancet. 2020; 395: 1516.

PubMed: https://pubmed.ncbi.nlm.nih.gov/32334650/ 